\title{
Butterfly biodiversity in the city is driven by the interaction of the urban landscape and species traits: a call for contextualised management
}

\author{
Clàudia Pla-Narbona $\cdot$ Constantí Stefanescu • Joan Pino • Francisco J. Cabrero-Sañudo • \\ Enrique García-Barros $\cdot$ Miguel L. Munguira $\cdot$ Yolanda Melero $($ D
}

Received: 19 March 2021 / Accepted: 22 September 2021 / Published online: 9 October 2021

(C) The Author(s) 2021

\begin{abstract}
Context Urbanisation is an environmental filter for many species that leads to community homogenisation, with a few species inhabiting isolated patches (e.g. public and private gardens and parks) embedded within the urban landscape. Promoting biodiversity in urban areas requires understanding which species traits allow species to survive the urban landscape.

Objectives The objective of this study was to assess how species traits and landscape factors combine to allow species functional groups to live in the city.
\end{abstract}

Supplementary Information The online version contains supplementary material available at https://doi.org/10.1007/ s10980-021-01347-y.

C. Pla-Narbona $\cdot$ C. Stefanescu

Natural Sciences Museum of Granollers, 08403 Granollers, Spain

e-mail: claudia.planarbona@gmail.com

C. Stefanescu

e-mail: canliro@gmail.com

C. Pla-Narbona · C. Stefanescu · J. Pino · Y. Melero ( $₫)$

CREAF, 08193 Cerdanyola del Vallés, Spain

e-mail: y.melero@creaf.uab.cat

J. Pino

e-mail: joan.pino@uab.cat

J. Pino $\cdot$ Y. Melero

Autonomous University of Barcelona,

08193 Cerdanyola del Vallés, Spain
Methods We used butterfly count data collected by volunteers in 24 gardens of Barcelona city, during 2018 and 2019. Species were clustered in functional groups according to their traits. We applied a multinomial choice model to test for the effect of the landscape on the different functional groups.

Results Three functional groups became prevalent in the city while a fourth, containing most sedentary specialist species, was filtered out. Although the observed groups had similar species richness, abundances varied depending on urban landscape characteristics. Specialist sedentary specialists and medium mobile species were all favoured by patch connectivity; while the presence of mobile generalist species was only enhanced by habitat quality. Our results

\author{
F. J. Cabrero-Sañudo \\ Biodiversity, Ecology and Evolution Department, \\ Complutense University of Madrid, 28040 Madrid, Spain \\ e-mail: fjcabrero@bio.ucm.es \\ E. García-Barros · M. L. Munguira \\ CIBC-UAM, Autonomous University of Madrid, \\ 28049 Madrid, Spain \\ e-mail: garcia.barros@uam.es \\ M. L. Munguira \\ e-mail: munguira@uam.es \\ Y. Melero \\ School of Biological Sciences, University of Reading, \\ Reading, UK
}


indicate that butterfly communities are more diverse in highly connected gardens.

Conclusions Our study highlights the need of contextualised management with actions accounting for the species functional groups, rather than a management focused on general species richness. It demonstrates that urban landscape planning must focus on improving connectivity inside the city in order to diversify the community composition.

Keywords Citizen science $\cdot$ Species traits $\cdot$ Urban landscape · Urban biodiversity · Butterfly metapopulations

\section{Introduction}

The worldwide urban cover is expected to increase two-to-six-fold in area (Seto et al. 2012; Gao and O'Neill 2020) up to at least 2050 (Chen et al. 2020). As cities continue to expand, they need to play a key role in biodiversity conservation by becoming suitable for a larger number of species of flora and fauna (Desrochers et al. 2011; Convention on Biological Diversity 2012). Consequently, several studies have investigated the relationship between landscape urbanisation and species richness and abundances, showing negative relationships for the majority of taxa (e.g. invertebrates including arthropods, as well as birds and mammals; Biard et al. 2017; Lagucki et al. 2017; Piano et al. 2017; Ramírez-Restrepo and MacGregor-Fors 2017; Merckx et al. 2018a, b; Fenoglio et al. 2020), with a few exceptions of positive (e.g. in aquatic invertebrates; Hill et al. 2017) or a lack of relationship (e.g. in arthropods; Christie and Hochuli 2009).

Urbanisation implies that during their evolutionary histories many species will increasingly encounter conditions they have not previously experienced. Since species with similar life histories and ecological traits (i.e. those that define species' ecological niches) respond similarly to specific perturbations (Murray et al. 2011; Wong and Candolin 2015; Melero et al. 2016), urbanisation can provoke fitness loss in many species if they possess traits that are maladapted to their new conditions (i.e. their original adaptive traits in natural environments are maladaptive in urban environments). By contrast, individuals of species with pre-adapted traits may be able to thrive in urban areas. Thus, an overall decline in trait richness could occur, leading to an overrepresentation of certain traits in urban communities (Lizée et al. 2011a; Sol et al. 2020). This functional homogenisation is often biased towards traits conferring wide niche breadths such as trophic generalism, dispersal ability, thermophilia and high reproductive rates (e.g. Piano et al. 2017; Merckx et al. 2018a, b; Santini et al. 2019; Melero et al. 2020).

The structure and composition of the urban landscape play a key role in the filtering of these traits (e.g. Blair and Launer 1997; Fenoglio et al. 2020). Indeed, the urban landscape is mostly composed of a built-up matrix, which reduces the abundance and connectivity of suitable habitat patches; furthermore, this matrix has a more serious negative impact on species distribution and abundance than matrices of (semi)natural areas (Blair and Launer 1997; Aronson et al. 2014; Oliveira et al. 2018; Melero et al. 2020). Urban green areas (i.e. potentially suitable patches) are usually small, isolated and greatly affected by the surrounding the built-up matrix (e.g. Verbeylen et al. 2003; Lizée et al. 2011b; Braaker et al. 2014; Melliger et al. 2017) and its surface area and composition (e.g. Bates et al. 2014; Tzortzakaki et al. 2019). Most research on urban homogenisation has linked environmental variables present in urban landscapes directly to community diversity and composition, or to species richness and abundance, without separating the specific effects of urban variables on the diversity of species traits (Ramírez-Restrepo and MacGregorFors 2017; Parris 2018). Yet, there is evidence that trait-specific effects exist in urban landscapes (e.g. Bates et al. 2014; Melliger et al. 2017; Iserhard et al. 2019). For example, the impact of connectivity and habitat composition may be greater on trophic specialists than on generalist species (Deguines et al. 2016; Wenzel et al.2020), or on less dispersive species (Melero et al. 2020). Patch area mostly seems to influence species of small body size (Wenzel et al. 2020). Hence, whether individuals of a species succeed or fail in urban areas may depend on a combination of certain species traits and the specific effect that urban drivers have on them (Fenoglio et al. 2021).

In this study, we analysed how species traits and landscape factors combine to allow individuals of a series of species to use suitable patches in the urban landscape. Specifically, we assessed how the 
probability that an individual occurs in a urban patch depends on the effect that the habitat quality (in terms of its similarity to surrounding (semi)natural areas) and the size and functional connectivity of the patches will have on the combination of species traits. We clustered species into functional groups (see Materials and methods) since species traits are known to occur in correlation rather than independently (Eskildsen et al. 2015; Middleton-Welling et al. 2018). We chose the above mentioned landscape variables given that they are key factors determining species presence (e.g. Melero et al. 2020) and are manageable features of the landscape. Butterflies were used as model species because they are recognised as good indicators of ecological and biodiversity effects (Pollard et al. 1996; Thomas 2005; Merckx et al. 2013) and respond quickly to habitat transformations (Krauss et al. 2010; Ubach et al. 2020). As well, butterflies possess a range of traits that are representative of insects and other short-lived species, thereby guaranteeing a wide

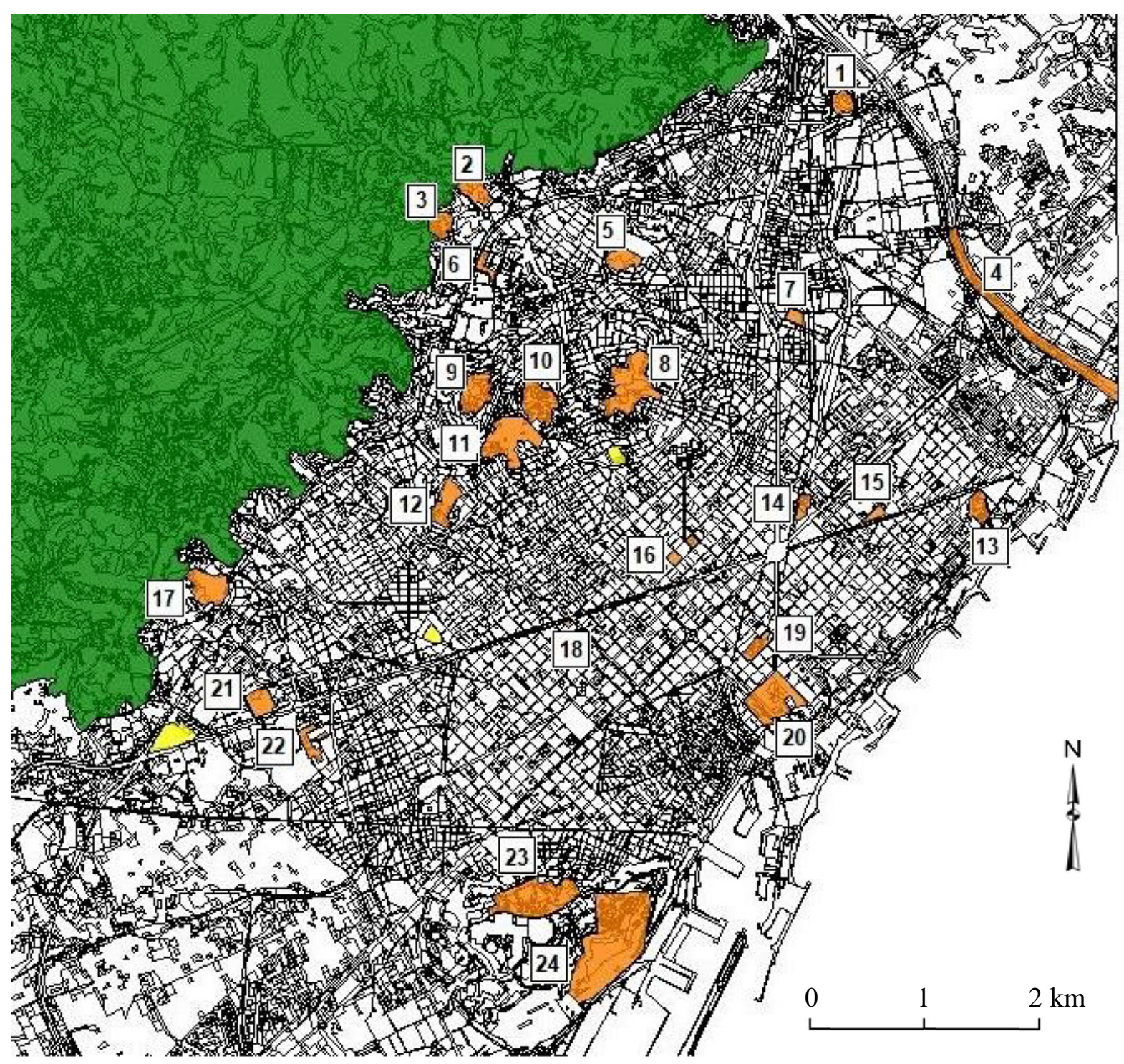

Fig. 1 Study area including the urban area of Barcelona, the adjacent sector of the Collserola Natural Park and the neighbouring towns. In green, the Natural Park; in orange the
24 urban gardens studied with their ID numbers (see Online resource 3 ). In yellow, the three discarded gardens 
range of ecological variations and ensuring reliable ecological predictions (Thomas 2005; Carnicer et al. 2013; Eskildsen et al. 2015). Our study was based on empirical count data gathered by a volunteer-based citizen-science project started in 2018 consisting of regular surveys of butterflies in a series of green areas (gardens and parks, 'gardens' hereafter) in the city of Barcelona.

We hypothesised that (i) for all functional groups, the probability that an individual butterfly would be present in a garden will increase with the increase in garden habitat quality, size and connectivity; but that (ii) the effect of these landscape variables would increase in importance on a gradient from wide- to narrow-breadth niche traits (i.e. from generalist highly mobile and high reproductive rate species, to specialists with limited mobility and low reproductive rates). Indeed, we expected that individuals at the extremes of these restrictive traits would be rare or even absent from the city.

\section{Materials and methods}

Study area and data collection

The study area was the city of Barcelona and its immediate conurbation, consisting of natural, (semi)natural and urban areas, resulting in a total of 12,600 ha of study area. Barcelona has c. 6,600 ha (52.4\% of the study area) covered by a dense urban matrix, the rest of the study area corresponding to the south-eastern part of the Collserola Natural Park3500 ha $(27.8 \%$ of the study area) known to be important for their species source effect (Melero et al. 2020) - and to 2500 ha of built-up areas in neighbouring cities and suburbs (19.8\% of the study area; Fig. 1).

Sampling was done by volunteers participating in the citizen science program urban Butterfly Monitoring Scheme or uBMS (ubms.creaf.cat), which consists of regular adult butterfly monitoring surveys from March to the end of September covering the flight period of most species in the area. Surveys were performed along 300-m transects within selected gardens following the standard 'Pollard walk' methodology (Pollard 1988). A total of 39 volunteers monitored 25 gardens in 2018 , the first year of the project, and 24 gardens in 2019 (total number of different gardens $=27$ ). Although our statistical methodology (Multinomial choice model) allows for unequal sampling, following a conservative approach we chose to discard from our analyses gardens with low survey efforts and only selected gardens monitored weekly, biweekly in two non-consecutive weeks or once per month during at least one of the study years. This selection resulted in a total of 24 selected gardens, comprising 318 ha of the total 335 ha of public and private gardens included in the program. The size of studied gardens ranged from 0.49 to 68.69 ha $($ mean $=13.77 \pm 15.23$ ha; Fig. 1$)$.

Landscape variables

The edges of the studied gardens were digitized on upto-date (2018) orthoimages generated by the Cartographic Institute of Catalonia. Then, land cover composition of these gardens was inferred from a land-cover map (a 5-m cell grid) obtained from the combination and reclassification of the Copernicus Urban Atlas (https://land.copernicus.eu/local/urbanatlas), the land cover map of Catalonia MCSC 2015 (https://www.creaf.uab.es/mcsc/), and the Spanish SIOSE Land Cover Map (https://www.siose.es/).

To gather garden habitat quality, we used a proxy based on the similarity of garden vegetation to the (semi)natural areas where butterfly species richness is greatest (catalanbms.org/ca/habitats/) given that previous research has highlighted the importance of native flora for many butterfly species (Graves and Shapiro 2003) and because our aim was to test the role of habitat quality on the functional groups rather than species-specific. Vegetation per garden was surveyed in situ and categorized into values ranging from zero to three according to the following criteria: 0: no vegetation cover; 1: non-native spontaneous and ornamental vegetation; 2: isolated native plants embedded within non-native vegetation; 3 : continuous native vegetation. We then calculated the habitat quality of each garden as the weighted mean of all four categories, i.e. the sum of the (numbered) categories multiplied by their area divided by the total area of the garden:

$Q_{i}=\frac{\sum\left(C_{i, j} \times A_{i, j}\right)}{A_{i}}$ 
Table 1 Estimated coefficients, their mean, SD (Standard deviation) and 97.50\% credible interval bounds for the probability of an individual to be present in a garden in relation to the standardised landscape covariates

\begin{tabular}{|c|c|c|c|c|c|}
\hline Cluster & Covariates & Estimate & SD & $2.50 \%$ & $97.50 \%$ \\
\hline \multirow[t]{5}{*}{ C2-sedentary intermediate specialists } & Habitat quality & 0.04 & 0.04 & -0.05 & 0.10 \\
\hline & Open vegetated area & 0.05 & 0.04 & -0.05 & 0.13 \\
\hline & Closed vegetated area & -0.06 & 0.08 & -0.20 & 0.09 \\
\hline & C500 & -0.21 & 0.15 & -0.48 & 0.07 \\
\hline & C1k & 0.34 & 0.17 & 0.10 & 0.73 \\
\hline \multirow[t]{5}{*}{ C3-forest specialists } & Habitat quality & 0.04 & 0.03 & -0.02 & 0.11 \\
\hline & Open vegetated area & -0.19 & 0.05 & -0.27 & -0.08 \\
\hline & Closed vegetated area & 0.09 & 0.04 & 0.01 & 0.16 \\
\hline & $\mathbf{C 5 0 0}$ & 0.30 & 0.12 & $\mathbf{0 . 0 2}$ & $\mathbf{0 . 5 0}$ \\
\hline & $\mathrm{C} 1 \mathrm{k}$ & -0.045 & 0.062 & -0.14 & 0.12 \\
\hline \multirow[t]{5}{*}{ C4-mobile generalists } & Habitat quality & -0.30 & 0.11 & -0.52 & -0.11 \\
\hline & Open vegetated area & 0.00 & 0.20 & -0.38 & 0.38 \\
\hline & Closed vegetated area & 0.30 & 0.14 & -0.02 & 0.56 \\
\hline & C500 & -0.53 & 0.42 & -1.03 & 0.55 \\
\hline & $\mathrm{C} 1 \mathrm{k}$ & -0.39 & 0.41 & -1.35 & 0.09 \\
\hline
\end{tabular}

Individual-specific covariates (i.e., clusters) are included in choice-specific covariates (i.e., landscape variables) with a '_CX' (where $\mathrm{X}$ is clusters' number). Significant effects are marked in bold

where $Q_{i}$ is the habitat quality of the garden $i, C_{j}$ is the vegetation category $j(0-3), A_{i j}$ is the area of that category $j$ at each garden $i$, and $A_{i}$ is the total area of the garden (Supplementary Information Fig. 1a and Table 1).

Garden size was assessed using three different metrics: (i) total garden area, including vegetated and non-vegetated areas; (ii) 'open' vegetated areas including grassland, shrubs, crops and ornamental vegetated areas known to be important for butterfly specialists from open areas (Ubach et al. 2020); and (iii) 'closed' vegetated areas, with stands of trees or isolated urban trees, important for butterflies adapted to closed areas (Suggitt et al. 2012; Ubach et al. 2020; Supplementary Information Fig. 1b, c and Table 1).

Connectivity was calculated for each surveyed garden in relation to all vegetated areas outside the focus garden, including the surveyed and non-surveyed gardens and the adjacent natural areas in the city. We used the 5-m land-cover grid with grid squares categorized as either vegetated (i.e. belonging either to open or closed vegetation categories) or nonvegetated. We then calculated the connectivity of each study garden using a modification of Hanski's index (Hanski 1998) that calculates the total of vegetated areas weighted by their cost distance to the garden edge:

$C_{i}=\sum_{j \neq i} p_{j} \times \exp \left(-\propto \times d_{i j}\right)$

where $C_{i}$ is the connectivity of the garden $i, p_{j}$ is each vegetated cell $j$ outside the garden $i$ in area units (0.0025 ha), and $d_{i j}$ is the cost distance from the edge of the garden $i$ to the centre of each vegetated cell $j$. Given the importance of the urban matrix in the dispersal of individual butterflies (Lizée et al. 2011b; Melero et al. 2020), we calculated the cost distance $\left(d_{i j}\right)$ using the Euclidean distance (in $\mathrm{m}$ ) to each vegetated cell $j$, weighted by a resistance value assigned to each land cover category based on previous studies (Lizée et al. 2011b; FernándezChacón et al. 2014; Lizée et al. 2016; see Supplementary Information Fig. 2 and Table 2). To assess the connectivity for diverse maximal distances of butterfly dispersal, we adjusted $\propto$ (the slope of the exponential function of $C_{i}$ ) to generate a value near zero $(0.001)$ in the exponential function of the model using three maximum dispersal distances $\left(d^{\prime}: 200,500\right.$ and 1,000 m; Supplementary Information Fig. 1d, e and Table 1). 


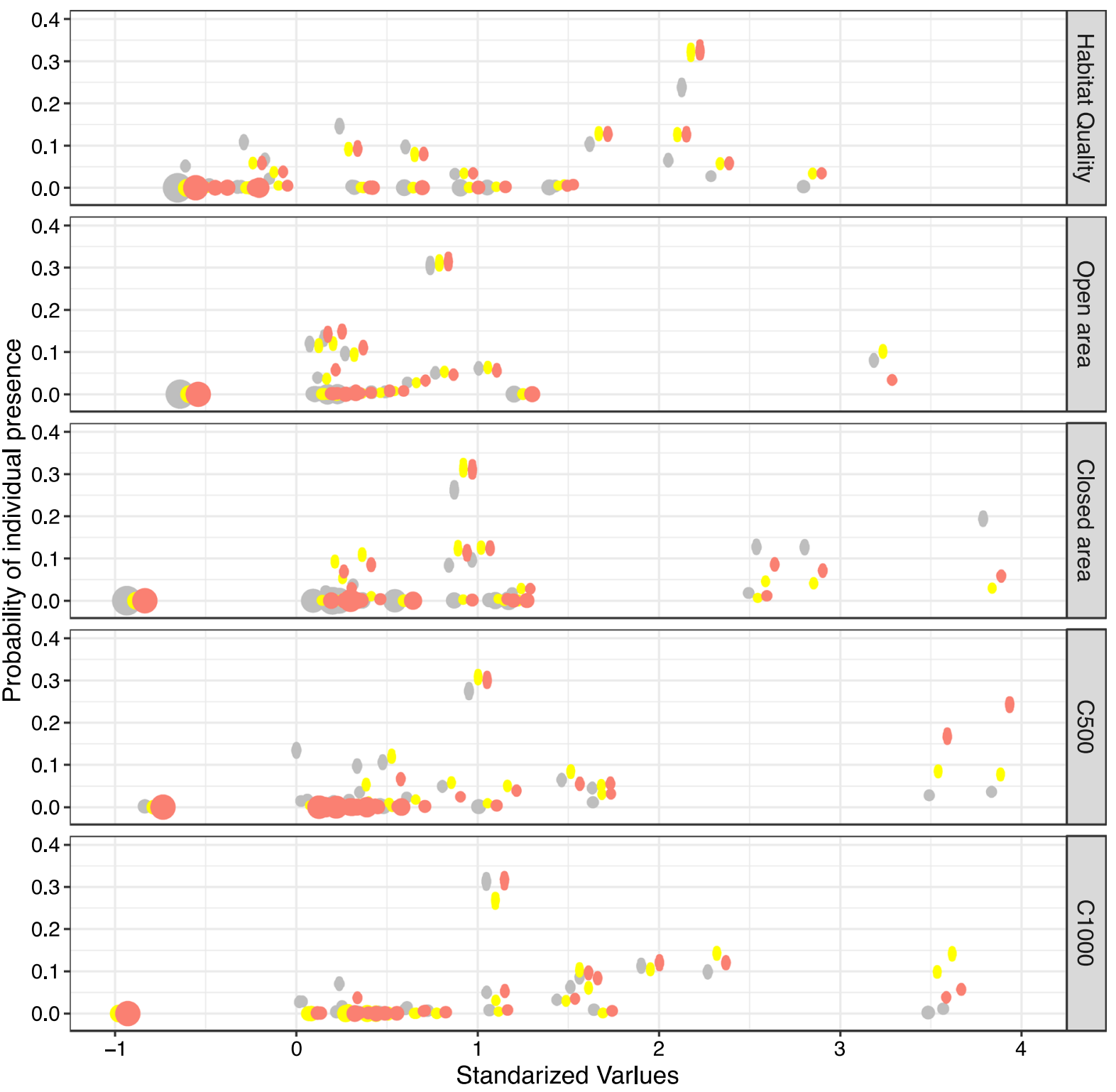

Fig. 2 Predicted probability of presence for each individual butterfly (coloured circles) in each garden in relation to the: habitat quality, open vegetated area, closed vegetated area, connectivity at small-scale (i.e., $500 \mathrm{~m}$ ) and connectivity at large-scale (i.e., $1 \mathrm{~km}$ ) (standardised values). In yellow C2sedentary intermediate specialists, in salmon C3-forest specialists and in grey C4-mobile generalists. To reduce superposition $\mathrm{a}+0.05$ jitter was applied to the covariate axis for the clusters

All seven patch and landscape variables were tested for significant correlations, which allowed us to select five uncorrelated variables: garden habitat quality,
$\mathrm{C} 2$ and $\mathrm{C} 3$. For each cluster, each individual observed $(\mathrm{N}=3545)$ is multiplied by the 24 potential gardens, giving a total of $9888,29,784$ and 45,408 probabilities for each cluster respectively. Predictions for each variable were based on fixing all the other covariates values at their mean. The size of the circles relates to the number of observations from one (smallest circles) to 100 observations (largest circles)

open vegetated area, closed vegetated area, and connectivity in buffers of $500 \mathrm{~m}$ and $1000 \mathrm{~m}$ (all five $\mathrm{r}<0.62$; Supplementary Information Table 3). 
Species traits, functional grouping and statistical modelling

We chose seven species traits known to be important in the behaviour and ecology of butterflies and in invertebrates in general (Stefanescu et al. 2011; Melero et al. 2016; Moretti et al. 2017; Merckx and Van Dyck 2019): adult habitat specialisation, larval specialisation, voltinism (i.e. the number of annual generations), overwintering stage, species temperature index, mobility ability and habitat openness preference (full description in Supplementary Information Table A1 of the Appendix 1).

These seven traits were used to separate the species into functional groups based on the co-occurrence of traits within species (Eskildsen et al. 2015; MiddletonWelling et al. 2018). Clustering was done using all butterfly species known to occur in the Mediterranean area of Catalonia, to which the study area belongs, in order to subsequently extract the cluster for each of the species observed in the sampled gardens for the modelling analysis. In total, 152 butterfly species are present in Catalonia, a figure that excludes rarely seen species $(<20$ observations over the past 24 years; catalanbms.org, Vila et al. 2018).

Hierarchical clustering was used to group these 152 species according to similarities between the speciesspecific values of their traits (species listed in Supplementary Information Table 4). We applied a Hill \& Smith principal component analysis, which performs a multivariate analysis with mixed categorical and continuous variables (Hill and Smith 1976). The best clustering method and optimal number of clusters were then determined following the criteria of elbow and silhouette graphics (for a complete explanation, see Appendix 1). Clustering was done using package ADE4 in R 3.5.3 (Dray and Dufour 2007; R Core Team 2020).

We used multinomial discrete choice models (multinomial regression models) to analyse the probability that an individual butterfly would be present in a particular garden. Multinomial models account for the ability of individuals to make choices based on gathered information, that is, that an individual $i$ (from a total of $N$ individuals) will select a patch (i.e. the gardens in our study) from a finite number of alternatives given the characteristics of the chosen patch, the alternative non-chosen patches and the individual (e.g. Vardakis et al. 2015; Melero et al.
2018). Thus, for each detected individual within the 24 gardens, the response variable was the garden in which the individual butterfly was observed (the choice), while the explanatory variables of this choice were related to the characteristics of the gardens (garden habitat quality, open vegetated area, closed vegetated area, connectivity in $500 \mathrm{~m}$ and $1000 \mathrm{~m}$ buffers) and the individual butterfly (the functional cluster it belongs to) (see model details in Appendix 2).

The model was fitted in a Bayesian framework using a Markow Chain Monte Carlo (MCMC) procedure, with the Package 'MNP' (Imai and van Dyk 2005). All independent continuous variables were standardised to reduce standard deviation. We set the Gaussian with 'infinite' variance, which are the default non-informative priors and drew 1,500,000 MCMC Gibbs samples, discarding the first 500,000, and retaining one from every 100 iterations for storagesaving purposes and predictions. Finally, we ran two independent MCMC chains, starting from over-dispersed values, to diagnose their convergence with the Gelman-Rubin statistic from package coda (Supplementary Information Table 5; Gelman and Rubin 1992).

\section{Results}

Functional grouping of butterfly species

For the set of 152 Catalonian butterfly species the divisive clustering method gave four as the optimal number of functional groups (Appendix 1). Cluster C1 $(\mathrm{N}=62$, hereafter $\mathrm{C} 1$-sedentary specialists) consisted of the least mobile species with the lowest reproductive rates, and the most specialist species in both larval and adult stages. This cluster included species that overwinter in the egg or larval stage. Cluster $\mathrm{C} 2(\mathrm{~N}=58$, $\mathrm{C} 2$-sedentary intermediate specialists) included species of low mobility, mostly overwintering in the larval stage (only 15 species overwinter in the pupal or egg stages). In terms of nectar sources, the species in this cluster were less specialist than those in $\mathrm{C} 1$, and were either uni- or multivoltine. Cluster $\mathrm{C} 3$ ( $\mathrm{N}=19$, C3forest specialists) was the only cluster composed of multivoltine forest specialist species (i.e. with preference for closed vegetated areas) that were also generalists of intermediate mobility. The cluster $\mathrm{C} 4$ ( $\mathrm{N}=13$, C4-mobile generalists) consists of highly 
mobile multivoltine generalist (both in larval and adult stage) species, with great temperature tolerance (Supplementary Information Table 6).

Of these 152 species used to create the four clusters, 36 were observed in gardens in the study area (total of 3545 individuals). No species from group C1-sedentary specialists were observed; 14 species and 412 individuals (11.6\% of all observations) of group C2sedentary intermediate specialists, 10 species and 1241 individuals $(35 \%)$ of $\mathrm{C} 3$-forest specialists, and 12 species and 1,892 individuals $(53.4 \%)$ of group C4mobile generalists were observed (Supplementary Information Table 7).

Landscape effects on contrasting functional groups

Although the probability that an individual butterfly would be detected in a garden varied between gardens and functional groups, the average probability that an individual butterfly would appear in a specific garden compared to any other garden was 0.042 , in a range of $0-0.361$ with a median $=0.02$, which demonstrates that some gardens were more attractive to certain butterflies than others. These preferences also varied between functional groups: $\mathrm{C} 2$-sedentary intermediate specialists and $\mathrm{C} 3$-forest specialists both had a lower median appearance probability of c. 0.01 , while C4mobile generalist butterflies, the most frequent species in the gardens, had a median appearance probability of 0.02 (Supplementary Fig. 3).

C2-sedentary intermediate specialists were positively affected by large scale connectivity $(1 \mathrm{~km})$ given that one unit of this large-scale connectivity increased by c. $33 \%$ the probability that a C2-butterfly would appear in a garden (effect size $=0.34, \mathrm{CI}=$ $0.1-0.73$ ). Connectivity also increased the probability of appearance of $\mathrm{C} 3$-forest specialists but at a lower spatial scale $(500 \mathrm{~m})$, and these species were more likely to be found in gardens with forested areas (i.e. closed vegetated areas) and less in open areas. Lastly, the most frequent, i.e. C4-mobile generalist butterflies, were independent of the landscape except for a negative effect of garden habitat quality determined by our proxy based on (semi)natural native vegetation (Table 1; Fig. 2).

\section{Discussion}

Using a volunteer based project in over 24 urban parks and gardens, we provided new evidence of how the urban landscape affects species presence in urban patches, and how this relationship is mediated by species traits grouped into functional clusters, a combination that has hitherto been generally overlooked in research (but see Delgado de la Flor et al. 2020). Although no functional C1-sedentary specialists were recorded in the city, a similar number of species from all other clusters were found; i.e. the species richness of $\mathrm{C} 2$-sedentary intermediate specialists, C3-forest specialists and C4-mobile generalists was broadly similar (14, 10 and 12 species, respectively). Both the raw abundances and the probability that individuals were present in the gardens declined as species mobility, reproductive rates and trophic generalisation all decreased. In fact, $\mathrm{C} 4$ was 4.5 and 1.5 times more abundant than $\mathrm{C} 2$ and $\mathrm{C} 3$, respectively. Our findings reveal that while overall species and functional richness are lower in urban environments than in natural areas (e.g. Biard et al. 2017; Merckx et al. 2018a; Fenoglio et al. 2020), the number of species in the different functional groups are similar. However, abundances differed between the functional groups, largely due to the lower likelihood of the presence of individual butterflies from the $\mathrm{C} 2$ and $\mathrm{C} 3$ clusters. High species abundance evenness has also been observed in terrestrial arthropods and bird species (Piano et al. 2020; Sol et al. 2020), which is potentially related to species traits (Sol et al. 2020).

Our hypothesis that more suitable, larger and better-connected gardens would favour the presence of all species independently of their functional group was partially fulfilled. Connectivity had no significant effect on C4-mobile generalists but its effects did increase from mobile generalist species to sedentary specialists (i.e. for C3-forest specialist species and C2sedentary intermediate specialists), supporting the key role of connectivity for less mobile species in urban environments (Braaker et al. 2017; Delgado de la Flor et al. 2017; Melero et al. 2020). Indeed, for these two clusters, connectivity was the only (for $\mathrm{C} 2$ ) or main (for C3) factor determining their presence. Connectivity for $\mathrm{C} 2$ needed a larger spatial scale $(1000 \mathrm{~m})$ than $\mathrm{C} 3(500 \mathrm{~m})$, even though $\mathrm{C} 2$ species were less mobile than $\mathrm{C} 3$ species. This result contrasts with 
previous research showing that smaller scales of connectivity are required for less mobile species (e.g. Merckx and Van Dyck 2019), probably due to the (semi)natural areas acting as a source of butterfly individuals. C3-forest specialist butterflies also preferred closed to open vegetation, as is the case of Pararge aegeria (Linnaeus 1758) and Gonepteryx rhamni (Linnaeus 1758). Of all groups, the C4-mobile generalists were least influenced by landscape characteristics and were the most likely to be present in any garden, as was to be expected since their traits (e.g. dispersal ability, trophic generalism; see Merckx et al. 2018a, b; Melero et al. 2020) are common in urban areas. A dominance of mobile generalist species in urban gardens, whether as city dwellers or transients, has also been observed in arthropods (Delgado de la Flor et al. 2017; Delgado de la Flor et al. 2020; Melero et al. 2020), birds (Bonier et al. 2007; Croci et al. 2008) and mammals (Santini et al. 2019). Despite the little effect that the urban landscape had on these species, there was a negative effect of garden habitat quality, which we attribute to the fact that in our approximate definition of habitat quality (associated with overall garden naturalness) we awarded low quality values to ornamental non-native plants. However, generalist species frequently feed on some of these plant species, in both larval and adult stages. For instance (Graves and Shapiro 2003), species of the genera Vanessa (Fabricius 1807), Pieris (Schrank 1801), Iphiclides (Hübner 1807) and Papilio (Linnaeus 1758 ) are all highly attracted to the non-native ornamental plants frequently planted in urban gardens (e.g. Buddleja davidii (Franchet 1887) in Barcelona). Thus, ornamental non-native vegetation can provide good habitat for generalist species, a finding that we failed to consider in our definition of habitat quality. A key strategy in further research that might help explain this counterintuitive result would be to use speciesspecific habitat approaches based on detailed information regarding plant resources (i.e. the amount of cover of all plant species) obtained from specific vegetation surveys.

Overall, there was no single set of garden characteristics that favoured all functional groups equally and simultaneously. Nevertheless, our results indicate that highly connected gardens are the most likely to harbour all functional groups, including the least abundant ones (C2-sedentary intermediate specialists and C3-forest specialists). Increasing the presence of these two groups, especially $\mathrm{C} 3$, will require combining areas of open and closed vegetation in gardens. Indeed, habitats with varied vegetation structure offer microhabitats that are suitable for a greater number of species (Sarthou et al. 2014; Sivakoff et al. 2018). Therefore, it is the combination of the barrier effect of the urban matrix and garden isolation (i.e. connectivity), together with the vegetation characteristics, that seems to not only shape butterfly richness-as previously observed (Lizée et al. 2016; Tzortzakaki et al. 2019)_but also the community composition of species based on their traits.

Worryingly, the C1-sedentary specialists were not present in any of the gardens and as such we were unable to analyse the trait-landscape interactions affecting them. It has been shown that garden isolation due to urbanisation creates an ecological barrier that prevents species lacking the traits required to overcome dispersal challenges (i.e. mobility or larval trophic specialisation) from colonising successfully (Braaker et al. 2017; Sivakoff et al. 2018; Melero et al. 2020). The lack of $C 1$ species and the low abundances of C2 and C3 paints a picture of overall community homogenisation and impoverishment in urban areas that has been observed in other studies of other groups (Beninde et al. 2015; e.g. in birds and butterflies, Aronson et al. 2014; Olivier et al. 2016; Merckx and Van Dyck 2019). In fact, our study revealed that these factors cause there to be almost 58\% fewer butterfly species in the city than in the surrounding (semi)natural areas, a very similar value to that found in Belgium for butterfly species richness (59\% lower in urban areas; Merckx \& Van Dyck 2019).

\section{Conclusions for practice}

Our findings demonstrate that any increase in urban biodiversity will require a diversification of functional community composition in terms of the key species traits and how the landscape affects them in different ways. Management actions need to target increases in species with no or low probability of presence and abundance in cities. Therefore, initial management efforts should concentrate on the low-occurring groups (C2-sedentary intermediate specialists and C3-forest specialists) by improving the connectivity between the city and (semi)natural areas; this will facilitate migration between suitable patches and 
promote population establishment in city patches whilst these species and those currently absent (C1sedentary specialists) attempt to overcome the colonization barriers imposed by the urban matrix (Melero et al. 2020). Further research could explore how different species use urban green areas and their flora (e.g. for breeding and feeding) and how this habitat use relates to species traits. Nevertheless, further data is needed if this line of study is to be followed.

Acknowledgements We would like to sincerely thank all the volunteers who gather the data for the uBMS project. The project was funded by Fundación Biodiversidad, the project MEDYCI PID2020-113133RB-I00 of the Spanish Ministry of Science and Innovation), and Barcelona and Madrid City Halls. Y.M. was supported by Marie Skłodowska Curie H2020MSCA-IF-2017 795890 project EXTINCT of the European Commission and a SEVERO OCHOA postdoctoral fellowship within the SO CEX-2018-000828-S of the Spanish Ministry of Science and Innovation. We thank the two reviewers for the useful comments and Michael Lockwood for the English revision of the manuscript.

Authors contributions YM conceived the idea and designed the methodology; YM, CS, MLM, EGB, FCS and JP initiated the project, with $\mathrm{YM}$ coordinating the volunteers that gathered the butterfly data; CP did the field work and performed the clustering, supervised by CS, JP and YM; CP and JP calculated the landscape variables; CP and YM fit the multinomial model, interpreted the results and wrote the manuscript. All authors edited the manuscript and gave final approval for publication.

Funding Open Access Funding provided by Universitat Autonoma de Barcelona. The project was funded by Fundación Biodiversidad and CREAF during 2018 and by the Barcelona and Madrid City Halls since 2019.

Data availability The datasets generated during the study will available in the Dryad repository upon acceptance.

\section{Declarations}

Conflict of interest The authors declare no conflict of interests.

Ethical approval The study did not include capturing individuals. Hence, no ethical approvals were needed.

Consent to participate Not applicable.

Consent for publication All authors agree on the publication of the current version.

Code availability The code of the model generated during the study will be available in the Dryad repository upon acceptance.
Open Access This article is licensed under a Creative Commons Attribution 4.0 International License, which permits use, sharing, adaptation, distribution and reproduction in any medium or format, as long as you give appropriate credit to the original author(s) and the source, provide a link to the Creative Commons licence, and indicate if changes were made. The images or other third party material in this article are included in the article's Creative Commons licence, unless indicated otherwise in a credit line to the material. If material is not included in the article's Creative Commons licence and your intended use is not permitted by statutory regulation or exceeds the permitted use, you will need to obtain permission directly from the copyright holder. To view a copy of this licence, visit http://creativecommons.org/licenses/by/4.0/.

\section{References}

Aronson MFJ, La Sorte FA, Nilon CH et al (2014) A global analysis of the impacts of urbanization on bird and plant diversity reveals key anthropogenic drivers. Proc Biol Sci 281:20133330

Bates AJ, Sadler JP, Grundy D et al (2014) Garden and landscape-scale correlates of moths of differing conservation status: significant effects of urbanization and habitat diversity. PLoS ONE 9:e86925

Beninde J, Veith M, Hochkirch A (2015) Biodiversity in cities needs space: a meta-analysis of factors determining intraurban biodiversity variation. Ecol Lett 18:581-592

Biard C, Brischoux F, Meillère A et al (2017) Growing in cities: an urban penalty for wild birds? A study of phenotypic differences between urban and rural great tit chicks (Parus major). Front Ecol Evol. https://doi.org/10.3389/fevo. 2017.00079

Blair RB, Launer AE (1997) Butterfly diversity and human land use: species assemblages along an urban grandient. Biol Conserv 80:113-125

Bonier F, Martin PR, Wingfield JC (2007) Urban birds have broader environmental tolerance. Biol Lett 3:670-673

Braaker S, Ghazoul J, Obrist MK, Moretti M (2014) Habitat connectivity shapes urban arthropod communities: the key role of green roofs. Ecology. https://doi.org/10.1890/130705.1

Braaker S, Obrist MK, Ghazoul J, Moretti M (2017) Habitat connectivity and local conditions shape taxonomic and functional diversity of arthropods on green roofs. J Anim Ecol 86:521-531

Carnicer J, Stefanescu C, Vila R et al (2013) A unified framework for diversity gradients: the adaptive trait continuum. Glob Ecol Biogeogr 22:6-18

Chen G, Li X, Liu X et al (2020) Global projections of future urban land expansion under shared socioeconomic pathways. Nat Commun 11:1-12

Christie FJ, Hochuli DF (2009) Responses of wasp communities to urbanization: effects on community resilience and species diversity. J Insect Conserv 13:213-221 
Croci S, Butet A, Clergeau P (2008) Does urbanization filter birds on the basis of their biological traits? Condor 110:223-240

Deguines N, Julliard R, de Flores M, Fontaine C (2016) Functional homogenization of flower visitor communities with urbanization. Ecol Evol 6:1967-1976

Delgado de la Flor YA, Burkman CE, Eldredge TK, Gardiner MM (2017) Patch and landscape-scale variables influence the taxonomic and functional composition of beetles in urban greenspaces. Ecosphere 8:e02007

Delgado de la Flor YA, Perry KI, Turo KJ et al (2020) Local and landscape-scale environmental filters drive the functional diversity and taxonomic composition of spiders across urban greenspaces. J Appl Ecol. https://doi.org/10.1111/ 1365-2664.13636

Desrochers RE, Kerr JT, Currie DJ (2011) How, and how much, natural cover loss increases species richness. Glob Ecol Biogeogr 20:857-867

Dray S, Dufour A-B (2007) The ade4 Package: implementing the duality diagram for ecologists. J Stat Softw 22:1-20. https://doi.org/10.18637/jss.v022.i04

Eskildsen A, Carvalheiro LG, Kissling WD et al (2015) Ecological specialization matters: long-term trends in butterfly species richness and assemblage composition depend on multiple functional traits. Divers Distrib 21:792-802

Fenoglio MS, Calviño A, González E et al (2021) Urbanisation drivers and underlying mechanisms of terrestrial insect diversity loss in cities. Ecol Entomol 46:757-771

Fenoglio MS, Rossetti MR, Videla M (2020) Negative effects of urbanization on terrestrial arthropod communities: A metaanalysis. Glob Ecol Biogeogr 29:1412-1429

Fernández-Chacón A, Stefanescu C, Genovart M et al (2014) Determinants of extinction-colonization dynamics in Mediterranean butterflies: the role of landscape, climate and local habitat features. J Anim Ecol 83:276-285

Gao J, O’Neill BC (2020) Mapping global urban land for the 21 st century with data-driven simulations and Shared Socioeconomic Pathways. Nat Commun 11:1-12

Gelman A, Rubin DB (1992) Inference from iterative simulation using multiple sequences. Stat Sci 7:457-472

Graves SD, Shapiro AM (2003) Exotics as host plants of the California butterfly fauna. Biol Conserv 110:413-433

Hanski I (1998) Metapopulation dynamics. Nature 396:41-49

Hill MJ, Biggs J, Thornhill I et al (2017) Urban ponds as an aquatic biodiversity resource in modified landscapes. Glob Chang Biol 23:986-999

Hill MO, Smith AJE (1976) Principal component analysis of taxonomic data with multi-state discrete characters. Taxon 25:249-255

Imai K, van Dyk DA (2005) MNP: R package for fitting the multinomial probit model. J Stat Softw 14:1-32

Iserhard CA, Duarte L, Seraphim N, Freitas AVL (2019) How urbanization affects multiple dimensions of biodiversity in tropical butterfly assemblages. Biodivers Conserv 28:621-638

Krauss J, Bommarco R, Guardiola M et al (2010) Habitat fragmentation causes immediate and time-delayed biodiversity loss at different trophic levels. Ecol Lett 13:597-605
Lagucki E, Burdine JD, McCluney KE (2017) Urbanization alters communities of flying arthropods in parks and gardens of a medium-sized city. PeerJ 2017:e3620

Lizée M-H, Manel S, Mauffrey J-F et al (2011a) Matrix configuration and patch isolation influences override the species-area relationship for urban butterfly communities. Landsc Ecol 27:159-169

Lizée MH, Mauffrey JF, Tatoni T, Deschamps-Cottin M (2011b) Monitoring urban environments on the basis of biological traits. Ecol Indic 11:353-361

Lizee M-H, Tatoni T, Deschamps-Cottin M (2016) Nested patterns in urban butterfly species assemblages: respective roles of plot management, park layout and landscape features. Urban Ecosyst 19:205-224

Melero Y, Cornulier T, Oliver MK, Lambin X (2018) Ecological traps for large-scale invasive species control: predicting settling rules by recolonising American mink post-culling. J Appl Ecol 55:1769-1779

Melero Y, Stefanescu C, Palmer SCF et al (2020) The role of the urban landscape on species with contrasting dispersal ability: Insights from greening plans for Barcelona. Landsc Urban Plan 195:103707

Melero Y, Stefanescu C, Pino J (2016) General declines in Mediterranean butterflies over the last two decades are modulated by species traits. Biol Conserv 201:336-342

Melliger RL, Rusterholz HP, Baur B (2017) Habitat- and matrix-related differences in species diversity and trait richness of vascular plants, Orthoptera and Lepidoptera in an urban landscape. Urban Ecosyst 20:1095-1107

Merckx T, Huertas B, Basset Y, Thomas J (2013) A global perspective on conserving butterflies and moths and their habitats. Key Top Conserv Biol 2:237-257

Merckx T, Souffreau C, Kaiser A et al (2018a) Body-size shifts in aquatic and terrestrial urban communities. Nature 558:113-116. https://doi.org/10.1038/s41586-018-0140-0

Merckx T, Kaiser A, Van Dyck H (2018b) Increased body size along urbanization gradients at both community and intraspecific level in macro-moths. Glob Change Biol 28:3837-3848. https://doi.org/10.1111/geb.12969

Merckx T, Van Dyck H (2019) Urbanization-driven homogenization is more pronounced and happens at wider spatial scales in nocturnal and mobile flying insects. Glob Ecol Biogeogr 28:1440-1455

Middleton-Welling J, Wade RA, Dennis RLH et al (2018) Optimising trait and source selection for explaining occurrence and abundance changes: a case study using British butterflies. Funct Ecol 32:1609-1619

Moretti M, Dias ATC, de Bello F et al (2017) Handbook of protocols for standardized measurement of terrestrial invertebrate functional traits. Funct Ecol 31:558-567

Murray KA, Rosauer D, McCallum H, Skerratt LF (2011) Integrating species traits with extrinsic threats: closing the gap between predicting and preventing species declines. Proc R Soc B 278:1515-1523

Oliveira IF, Lion MB, Cardoso MZ (2018) A plaza too far: High contrast in butterfly biodiversity patterns between plazas and an urban reserve in Brazil. Landsc Urban Plan 180:207-216

Olivier T, Schmucki R, Fontaine B et al (2016) Butterfly assemblages in residential gardens are driven by species' habitat preference and mobility. Landsc Ecol 31:865-876 
Parris KM (2018) Existing ecological theory applies to urban environments. Landsc Ecol Eng 14:201-208

Piano E, De Wolf K, Bona F et al (2017) Urbanization drives community shifts towards thermophilic and dispersive species at local and landscape scales. Glob Chang Biol 23:2554-2564

Piano E, Souffreau C, Merckx T et al (2020) Urbanization drives cross-taxon declines in abundance and diversity at multiple spatial scales. Glob Chang Biol 26:1196-1211

Pollard E (1988) Temperature, rainfall and butterfly numbers. J Appl Ecol 25:819

Pollard E, Rothery P, Yates TJ (1996) Annual growth rates in newly established populations of the butterfly Pararge aegeria. Ecol Entomol 21:947-952

R Core Team (2020) R: A language and environment for statistical computing. R foundation for statistical computing, Vienna. https://www.R-project.org/

Ramírez-Restrepo L, MacGregor-Fors I (2017) Butterflies in the city: a review of urban diurnal Lepidoptera. Urban Ecosyst 20:171-182

Santini L, González-Suárez M, Russo D et al (2019) One strategy does not fit all: determinants of urban adaptation in mammals. Ecol Lett 22:365-376

Sarthou JP, Badoz A, Vaissière B et al (2014) Local more than landscape parameters structure natural enemy communities during their overwintering in semi-natural habitats. Agric Ecosyst Environ 194:17-28

Secretariat of the Convention on Biological Diversity (2012) Cities and biodiversity outlook. A global assessment of the links between action and policy: Urbanization, biodiversity, and ecosystem services. Montreal

Seto KC, Güneralp B, Hutyra LR (2012) Global forecasts of urban expansion to 2030 and direct impacts on biodiversity and carbon pools. Proc Natl Acad Sci USA 109:16083-16088

Sivakoff F, Prajzner S, Gardiner M (2018) Unique bee communities within vacant lots and urban farms result from variation in surrounding urbanization intensity. Sustainability 10:1926

Sol D, Trisos C, Múrria C et al (2020) The worldwide impact of urbanisation on avian functional diversity. Ecol Lett 23:962-972
Stefanescu C, Carnicer J, Peñuelas J (2011) Determinants of species richness in generalist and specialist Mediterranean butterflies: the negative synergistic forces of climate and habitat change. Ecography 34:353-363

Suggitt AJ, Stefanescu C, Páramo F et al (2012) Habitat associations of species show consistent but weak responses to climate. Biol Lett 8:590-593

Thomas JA (2005) Monitoring change in the abundance and distribution of insects using butterflies and other indicator groups. Philos Trans R Soc Lond B Biol Sci 360:339-357

Tzortzakaki O, Kati V, Panitsa M et al (2019) Butterfly diversity along the urbanization gradient in a densely-built Mediterranean city: Land cover is more decisive than resources in structuring communities. Landsc Urban Plan 183:79-87

Ubach A, Páramo F, Gutiérrez C, Stefanescu C (2020) Vegetation encroachment drives changes in the composition of butterfly assemblages and species loss in Mediterranean ecosystems. Insect Conserv Divers 13:151-161

Vardakis M, Goos P, Adriaensen F, Matthysen E (2015) Discrete choice modelling of natal dispersal: "Choosing" where to breed from a finite set of available areas. Methods Ecol Evol 6:997-1006

Verbeylen G, De Bruyn L, Adriaensen F et al (2003) Does matrix resistance influence Red squirrel (Sciurus vulgaris L. 1758) distribution in an urban landscape? Landscape Ecol 18:791-805

Vila R, Stefanescu C, Sesma JM (2018) Guia de les papallones diürnes de Catalunya. Lynx Edicions, Barcelona

Wenzel A, Grass I, Belavadi VV, Tscharntke T (2020) How urbanization is driving pollinator diversity and pollination - A systematic review. Biol Conserv 241:108321

Wong BBM, Candolin U (2015) Behavioral responses to changing environments. Behav Ecol 26:665-673

Publisher's Note Springer Nature remains neutral with regard to jurisdictional claims in published maps and institutional affiliations. 